Turco, G. (1959). J. gen. Microbiol. 21, 510-518

\title{
Changes in Cellular Ribonucleic Acid during Growth of Vesicular Stomatitis Virus in Chick Cell Culture
}

\author{
By G. TURCO* \\ Division of Biology, California Institute of Technology, Pasadena, \\ California, U.S.A.
}

\begin{abstract}
SUMMARY: The nuclei and small-particle (mitochondria + microsomes) fractions, separated from in vitro cultured chick embryo cells during one-step growth of vesicular stomatitis virus, were fractionated into $\mathrm{RNA}$ nucleotides by $\mathrm{NaCl}$ extraction, hydrolysis and paper electrophoresis. This allowed determination of molar and specific activity ratios of the RNA nucleotides during complementary ${ }^{32} P$ 'gain' and 'loss' experiments. Early exponential virus release coincided with a significant increase in uridine content of nuclear and small-particle RNA over uninfected values, and a decrease in specific activity of small-particle RNA uridylic acid in ${ }^{32} \mathrm{P}$ gain experiments. Other fractions showed no change. This suggested a relatively large synthesis of an RNA different from cellular RNA and containing a high proportion of uridine at a time when virus nucleic acid synthesis was probably at its peak. This synthesis appeared to be balanced by a simultaneous breakdown of preexisting RNA.
\end{abstract}

The study of pathways of phosphorus metabolism in chick embryo cells infected with vesicular stomatitis (VS) virus has shown an inhibition of phosphorus incorporation into the components of the infected cells (Cooper, 1957b). This inhibition appears to begin with the period of exponential virus release. The total amounts and the proportion of the various cellular phosphorus fractions, however, do not change appreciably. The absence of important changes in the various phosphorus fractions may be interpreted in two ways. Either the synthesis of viral nucleic acid and protein involves a very small fraction of the total cellular nucleic acid; or the cellular nucleic acid turns over internally without any over-all changes in amount. Whichever change occurs, the synthesis of new nucleic acids may cause detectable changes in purine or pyrimidine base ratios and in nucleotide specific activities; possibly it might lead to the appearance of some unusual base. The localization of such changes might also indicate the site of virus reproduction. The results given below confirm the smallness of the over-all changes produced by infection, but show significant changes in ribonucleic acid (RNA) base composition. These results suggest an appreciable and perhaps large synthesis of a type of RNA different from that in uninfected cells, and occurring during the early exponential virus release period, while pre-existing RNA is simultaneously broken down.

* Present address : Istituto di Clinica Medica, Corso Polonia 14, Torino, Italy. 


\section{METHODS}

General type of experiment. The RNA components of different particulate fractions of infected and non-infected cells were compared at different times during the latent and early release period of one-step ${ }^{32} \mathrm{P}$ 'gain' and 'loss' experiments (Cooper, $1957 b$ ). Since Cooper found that deoxyribonucleic acid incorporated or lost practically no ${ }^{32} \mathrm{P}$ during the infective process, the analyses were limited to the RNA. The sucrose-soluble fraction as obtained contained too low a concentration of RNA to be handled satisfactorily by present methods; only a few assays were performed on this fraction. In general these. assays yielded results very similar to those obtained with the small-particle fraction. Simultaneous virus assays were performed on the medium, and gave results identical with those to be expected from the reproducible type of experiments described by Cooper (1957a) which were performed in the same laboratory at the same time as the experiments described here. Thus the times and conditions of infection in the two sets of work are closely comparable. The preparation of stocks and of tissue cultures, the conditions of infection; the 1-step growth-curve method, the virus assay method and the media used. were described by Cooper (1957a).

${ }^{32} \boldsymbol{P}$ gain experiments. Six experiments of this type were carried out, representing six time-points during the growth cycle. Each experiment involved 30 monolayer cultures of cells from 10-day chick embryos, used when $24 \mathrm{hr}$. old and containing $c .2 \times 10^{7}$ cells. The medium was removed and $15 \mathrm{cul}-$ tures were completely infected with $2-3 \times 10^{8}$ plaque-forming units (pfu) of vesicular stomatitis virus in $0.5 \mathrm{ml}$. medium (average multiplicity of infection $=10 \mathrm{pfu} / \mathrm{cell}$ ), the remainder receiving $0.5 \mathrm{ml}$. medium as control. The cultures were incubated at $37^{\circ}$ in a $5 \%(\mathrm{v} / \mathrm{v}) \mathrm{CO}_{2}$-air mixture for $30 \mathrm{~min}$., when $1-3 \mu \mathrm{c} .{ }^{32} \mathrm{P}$ phosphate in $5 \mathrm{ml}$. medium were added to each infected and control culture. At times appropriate to each experiment during a further 2-6 $\mathrm{hr}$. period at $37^{\circ}$, the medium was removed for virus assay and the cells of all cultures washed with Earle's saline (Earle et al. 1943) and quantitatively. collected from the dishes with $2.5 \mathrm{mg}$. trypsin/ml. in Earle's saline; all control cultures and all infected cultures of any one experiment, respectively, were pooled to make one large control and one lärge infected cell sample for each time-point.

${ }^{32} \mathrm{P}$ loss experiments. Four experiments of this type were performed, using the same number and kind of monolayers as in the gain experiment. Without removing the medium, ${ }^{32} \mathrm{P}$ phosphate was added (1-3 $\mu \mathrm{c}$./monolayer) to $24 \mathrm{hr}$. cultures which were replaced at $37^{\circ}$ for $12 \mathrm{hr}$. and then washed three times with Earle's saline. Half of the cultures were infected as before, the remainder receiving medium only. After $30 \mathrm{~min}$. to allow for virus adsorption $5 \mathrm{ml}$. fresh medium were added, and the cells harvested and pooled as before at: various intervals between 3 and $6 \mathrm{hr}$. after infection.

Separation of cell particulate fractions. In both gain and loss experiments the harvested cells were washed twice with $0.25 \mathrm{~m}$-sucrose and homogenized in less than $0.3 \mathrm{ml}$. of 0.25 M-sucrose, according to the method of Hogeboom, Schneider 
\& Striebich (1953). By differential centrifugation three fractions were collected: $(a)$ nuclei, sedimented for $5 \mathrm{~min}$. at $700 \mathrm{~g}$; $(b)$ mitochondria + microsomes (here called small-particle fraction), obtained from the supernatant fluid of the nuclei by sedimenting together for $25 \mathrm{~min}$. at $60,000 \mathrm{~g}$; (c) the final supernatant fluid (soluble fraction).

Separation of chemical fractions. The method of Davidson \& Smellie (1952) was used for the separation and the quantitative determination of the ribonucleotides in the various fractions. After $\mathbf{l ~ h r}$. precipitation with trichloroacetic acid $(10 \%, \mathrm{w} / \mathrm{v})$ at $4^{\circ}$, followed by two washings of the precipitate with trichloroacetic acid, lipids were extracted with ethanol + chloroform mixture $(3: 1, v / v)$ at $75^{\circ}$ three times for $10 \mathrm{~min}$. each time, and with ether twice at room temperature for $15 \mathrm{~min}$. each time. The residue was extracted three times with $10 \mathrm{ml}$. of $100 \mathrm{~g}$. $\mathrm{NaCl} / \mathrm{l}$. solution for $1 \mathrm{hr}$. at $100^{\circ}$. The extract $(30 \mathrm{ml}$.) was precipitated overnight at $0^{\circ}$ with $60 \mathrm{ml}$. of $10 \%(\mathrm{v} / \mathrm{v})$ acetic acid in ethanol containing $10 \mathrm{mg}$. $\mathrm{MgCl}_{2}$. The precipitate was centrifuged down, redissolved in $4 \mathrm{ml}$. water and centrifuged to remove the insoluble residue. The nucleic acid was then precipitated from the clear supernatant fluid by addition of $8 \mathrm{ml}$. ethanol, washed with $2 \mathrm{ml}$. ethanol, dried with ether and hydrolysed with $0.3 \mathrm{~N}-\mathrm{KOH}$ at $37^{\circ}$ overnight. This solution was brought to $\mathrm{pH} 1$ with $\mathrm{HClO}_{4}$ and-the precipitate of $\mathrm{DNA}$, protein and $\mathrm{KClO}_{4}$ discarded. The supernatant fluid was concentrated under a current of air and the $\mathrm{pH}$ brought to 3.5-4.0 with $0.1 \mathrm{~N}-\mathrm{KOH}$. Volumes (30-50 $\mu \mathrm{l}$.) of this hydrolysate were separated by paper electrophoresis for $4 \mathrm{hr}$. at $700 \mathrm{~V}$. (Davidson \& Smellie, 1952); the spots were identified by ultraviolet (u.v.) photography (Markham \& Smith, 1949, 1951) cut out and eluted with $0 \cdot 1 \mathrm{~N}-\mathrm{HCl}$ at room temperature for $24 \mathrm{hr}$.

The quantity of nucleotide in each eluate was determined by a Beckman u.v. spectrophotometer and the radioactivity measured with a Nuclear Instrument and Chemical Corp. (Chicago) automatic end-window Geiger counter, making allowance for background counts and radioactive decay as usual. The determinations were made at the following wavelengths: adenylic acid $257 \mathrm{~m} \mu$, cytidylic acid $278 \mathrm{~m} \mu$, guanylic acid $257 \mathrm{~m} \mu$, uridylic acid $262 \mathrm{~m} \mu$, both for the spots and for corresponding blanks cut in the paper in similar positions; the extinctions were divided by the following values to obtain the millimolar $(\mathrm{mM})$ concentrations: adenylic acid $14 \cdot 4$, cytidylic acid 13 , guanylic acid 12·4, uridylic acid $9 \cdot 9$. From the nucleotide concentrations the nucleotide $\mathbf{P}$ concentrations were calculated, giving with radioactivity assays the specific activity (as counts/min./ $\mu \mathrm{g} . \mathbf{P}$ ).

\section{RESULTS}

All data are considered by comparing infected with uninfected (control) values at various stages during a virus growth cycle. The specific radioactivity data are treated in two ways, either by comparing with controls the absolute values of the specific activities of the individual nucleotides derived from the different RNA's, or by comparing nucleotide specific activity ratios (adenylic 
acid $=10$ ). The nucleotide compositions are compared as molar ratios (adenine $=10$ ). In comparing the specific activity and molar ratios of the four nucleotides, advantage was taken of the fact that the corresponding ratios in control cultures did not change with time of incubation, so that all ratios, both control and infected, are presented in terms of the average of uninfected values $(=100)$.

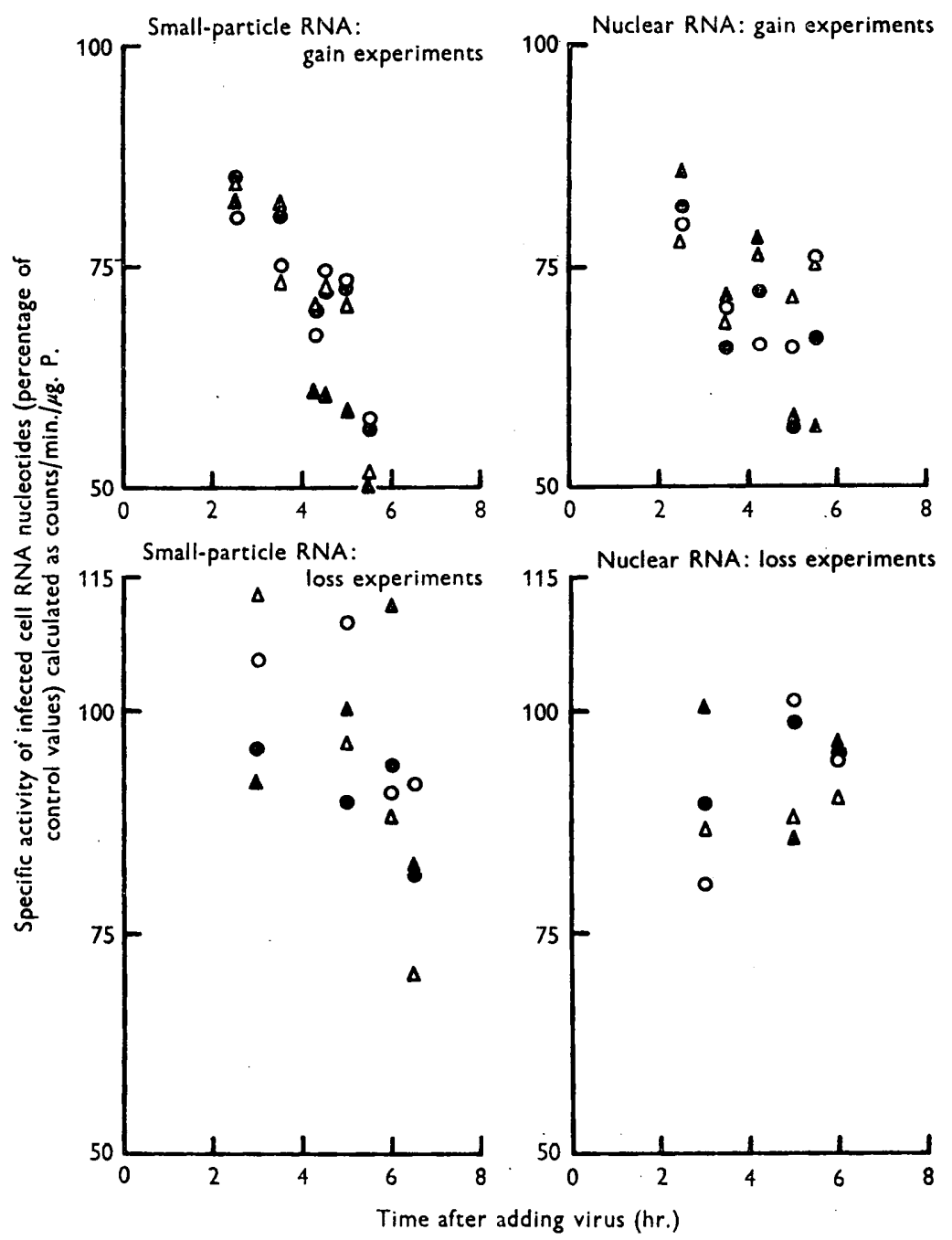

Fig. 1. The effect of vesicular stomatitis virus infection on the absolute specific activities of nucleotides extracted from RNA of small-particle and nuclear fractions during ${ }^{32} \mathbf{P}$ gain and loss experiments. The experiments are the same as those of Tables 1 and 2, where specific activity ratios (adenylic acid $=10$ ) rather than absolute values are presented. The absolute specific activities are calculated in terms of counts ${ }^{32} \mathbf{P} / \mathbf{m i n} . / \mu \mathrm{g} . \mathbf{P}$, and are expressed as percentages of the corresponding control values. $O$, cytidylic acid; $\odot$, adenylic acid; $\triangle$, guanylic acid; and $\Delta$, uridylic acid. 


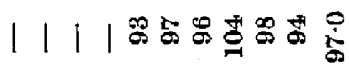

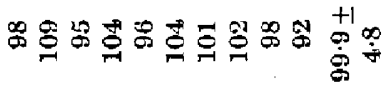

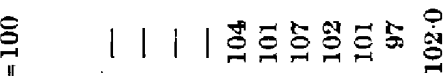

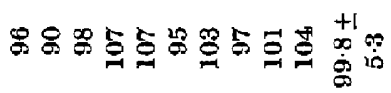
0000 un ma

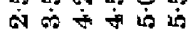

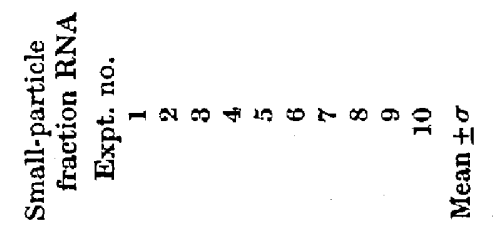


Ribonucleic acid and virus growth

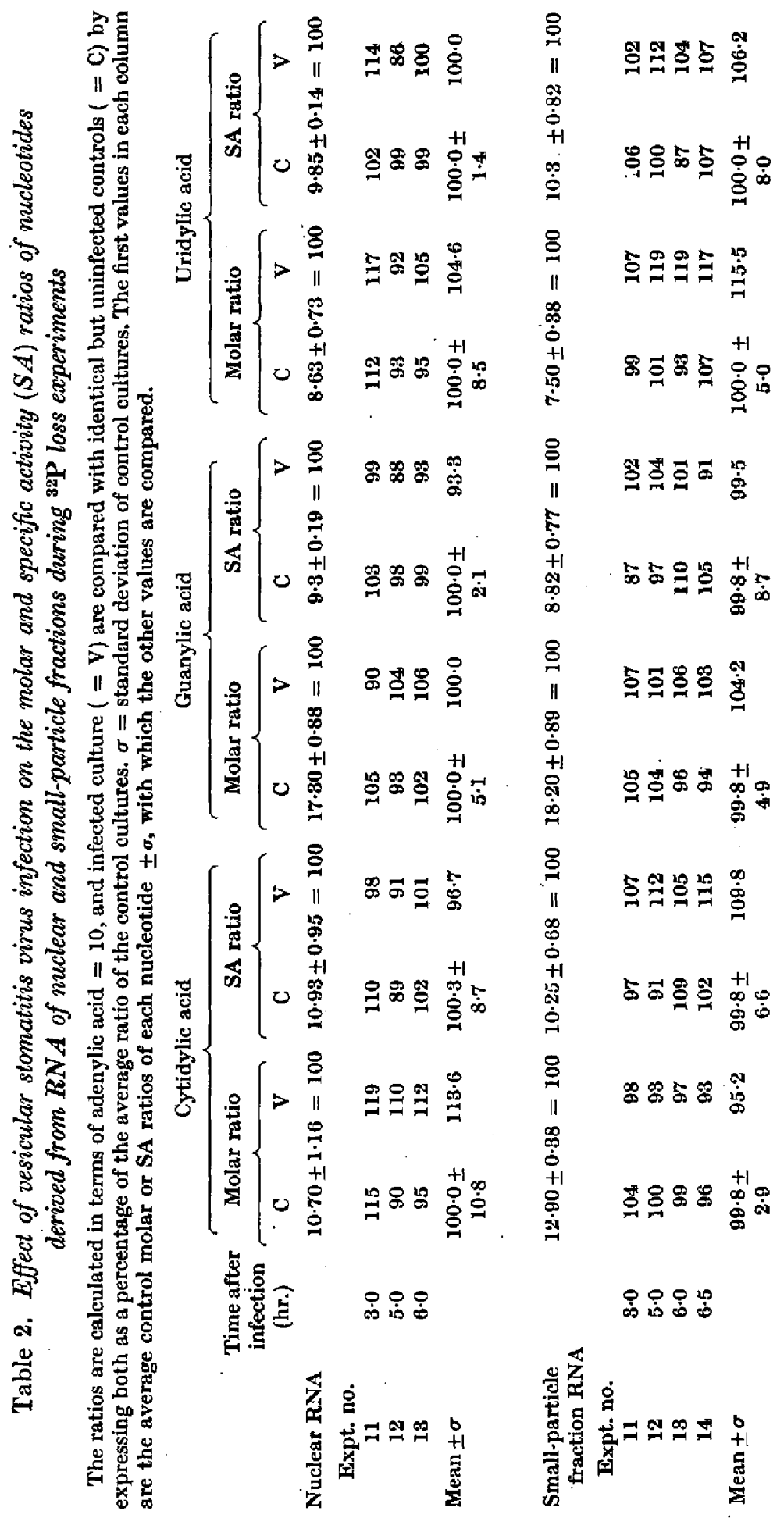


Specific activities of $R N A$ nucleotides during ${ }^{32} \mathrm{P}$ gain experiments

Nuclear $R N A$. The absolute specific activities progressively dropped well below control values for all nucleotides (Fig. 1); the relative specific activity ratios were unchanged (Table 1).

Small-particle $R N A$. The absolute specific activities also dropped well below controls for all nucleotides (Fig. 1). The relative specific activity of uridylic acid decreased consistently and significantly (Table 1), but the other nucleotides were unaffected.

Specific activities of $R N A$ nucleotides during ${ }^{32} P$ loss experiments

Nuclear $R N A$. The absolute specific activities were marginally lower than control (Fig. 1). There was no change in the relative specific activities (Table 2), except for a barely significant decrease in the specific activity of guanylic acid.

Small-particle $R \boldsymbol{N A}$. There were barely significant decreases in the absolute specific activities of the last samples (Fig. 1), and no significant change in relative specific activity of any nucleotide (Table 2).

Changes in molar ratios of $R N A$ bases during virus infection

Data from gain and loss experiments here served as duplicates.

Nuclear $R N A$. There was a significant and consistent increase in the proportion of uridylic acid in the gain experiments of Table 1 (not shown in the loss experiments of Table 2 which, however, probably have too few points to be significant). The other nucleotides showed no change.

$S$ mall-particle $R N A$. There was a significant and consistent increase in the proportion of uridylic acid in both gain and loss experiments (Tables 1 and 2), appearing 4-5 hr. after infection. The other nucleotides showed no significant change.

\section{DISCUSSION}

Four points of interest derived from these experiments may be considered. (1) There was a noticeably lower rate of ${ }^{32} \mathrm{P}$ incorporation into the nucleotides of infected cell RNA as compared with non-infected cells (absolute specific activity during gain experiments becoming lower in infected than in control cells). This effect occurred during the period of virus release and was also observed by Cooper $(1957 b)$ in nearly all other phosphate fractions. (2) While infection slowed ${ }^{32} \mathrm{P}$ uptake into RNA, it caused little selective early liberation of ${ }^{32} \mathrm{P}$ from pre-labelled RNA nucleotides (absolute specific activity being stable during ${ }^{32} \mathrm{P}$ loss experiments). The total amounts of RNA and nearly all other phosphate fractions also remained unchanged (Cooper, $1957 b$ ) indicating that early over-all lysis must be slight. (3) There were no very marked changes in the chemical composition of the RNA after infection; not only was no new base noticed, but the quantitative relationships between the pre-existing bases did not shift greatly. There was, however, a moderate but quite significant increase in the proportion of the uridylic acid in both small-particle and nuclear RNA of infected cells; this increase was accompanied by a decrease in relative specific activity of uridylic acid in the gain experiments (small- 
particle fraction RNA only). (4) The nucleotide specific activity ratios were a little, but usually significantly, different from unity. Without knowledge of the precursor nucleotide pools it is not possible to speculate on the meaning of this. The base ratios of the RNA of nuclear and small-particle fractions did not differ significantly, a finding which distinguishes these cells from those of, for example, rat liver, in which Crosbie, Smellie \& Davidson (1953) and Elson \& Chargaff (1952) found that the nuclear RNA was richer in uridylic and

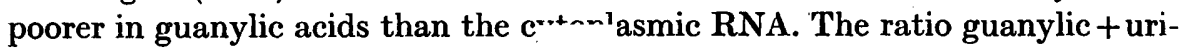
dylic:adenylic + cytidylic averaged $\mathbf{n}$ both control and infected cells, but there was a marginally significant auference in the ratio guanylic + cytidylic:adenylic + uridylic, which was 1.65 for infected cells and 1.53 for control cells. This was due mostly to the differences in uridylic acid.

The finding most relevant to the problem of vesicular stomatitis virus synthesis is the increase in proportion of uridylic acid in both nuclear and small-particle fraction RNA, with its decrease of relative specific activity in the small-particle fraction of the ${ }^{32} \mathrm{P}$ gain experiments. These changes cannot be due to increased synthesis of RNA uridylic acid directly from the ${ }^{32} \mathrm{P}$ of the medium since in gain experiments its relative and absolute specific activities were lower than in control cultures. The changes may represent a general breakdown of that cellular RNA existing before infection, leaving a small high-uridine residue undegraded, but the only RNA lysed by 5-6 hr. after infection (Cooper, 1957 b) was a small part of the soluble fraction RNA (not nuclear or small-particle fractions), and it is very unlikely that this would be large enough at 4-5 hr. to account for the size of the change found. Also this would not account for the lower than normal relative specific activity of uridylic acid found in the small-particle fraction RNA of infected cells during the gain experiments.

An alternative explanation which would account for this, however, is a synthesis of a new high-uridine RNA from mono- or polynucleotides already fabricated, perhaps derived from pre-existing nucleotide pools, but possibly also directly converted (via nucleotide pools?) from pre-existing RNA. This new RNA is different from the bulk of pre-existing RNA, but could conceivably be found in small amounts in normal cells. If the new RNA is not composed exclusively of uridylic acid it must account for an appreciable portion of the RNA of the cell. Since the total RNA is neither much increased nor decreased during this significant synthesis (Cooper, 1957 $b$ ) one must suppose that some pre-existing RNA is broken down while the new RNA is constructed, so that some interconversion of RNA is certainly likely.

The results therefore indicate that appreciable amounts of a new RNA are made and appear in both nucleus and cytoplasm at a time when synthesis of virus nucleic acid is expected to be at its height; synthesis of this new RNA appears to be balanced by destruction of some pre-existing RNA. The source of the new RNA is probably pre-existing nucleotides, either from precursor nucleotide pools or from RNA. The relationship of the new RNA to virus nucleic acid is unknown; it must be very much larger in amount than that nucleic acid which is eventually incorporated into infective virus. 
Essential questions are whether or not vesicular stomatitis virus contains RNA and, if so, whether its composition is similar to that found in infected cells, particularly in its high uridine content. If the new RNA is actually virus nucleic acid, this presents a quite different picture of animal virus growth than that to be expected from the small amounts of infective virus liberated. Thus animal viruses may be more like plant and bacterial viruses than they have hitherto appeared in that, rather than involving a small synthesis, the cell may become taken up with virus material. This implies that a major difference between plant and bacterial viruses on the one hand, and animal vi ruses on the other, is that the latter have a relatively low efficiency of making infective particles.

I am grateful to Dr R. Dulbecco for stimulating guidance and criticism and to Dr P. D. Cooper for help with the growth curves and the manuscript. I wish to acknowledge grants from the American Cancer Society Inc., and the American Cancer Society, California Division.

\section{REFERENCES}

COOPER, P. D. (1957a). Some characteristics of vesicular stomatitis virus growthcurves in tissue culture. J. gen. Microbiol. 17, 327.

Cooper, P. D. (1957b). Paths of phosphate transfer in normal chick embryo cells and in cells infected with vesicular stomatitis virus. J. gen. Microbiol: 17, 335 .

Crosbie, G. W., Smellie, R. M. \& Davidson, J. N. (1953). Phosphorus compounds in the cell. 5. The composition of the cytoplasmic and nuclear ribonucleic acids of the liver cell. Biochem. J. 54, 287.

Davidson, J. N. \& Smellie, R. M. (1952). Phosphorus compounds in the cell. 2. The separation by ionophoresis on paper of the constituent nucleotides of ribonucleic acid. Biochem. J. 52, 594.

Earle, W. R., Schilling, E. L., Stark, T. H., Straus, N. P., Brown, M. F. \& Shelton, E. (1943). Production of malignancy in vitro. IV. Mouse fibroblast cultures and changes seen in living cells. J. nat. Cancer Inst. 4, 165.

Elson, D. \& Chargaff, E. (1952). Observations on RNA composition in sea urchin embryos and in mammalian cell fractions. Symposium on Phosphorus Metabolism, 2, 329. Ed. by McElroy; W. D. and Glass, B. Baltimore: Johns Hopkins Press.

Hogeboom, G. H., Schneider, W. C. \& Striebrch, M. J. (1953). Localization and integration of cellular function. Cancer Res. 13, 617 .

Markham, R. \& SMrth, J. D. (1949). Chromatographic studies of nucleic acids. 1. A technique for the identification and estimation of purine and pyrimidine bases, nucleosides and related substances. Biochem. J. 45, 294.

MARKHAM, R. \& Smith, J. D. (1951). Chromatographic studies of nucleic acids. 4. The nucleic acid of the turnip yellow mosaic virus, including a note on the nucleic acid of the tomato bushy stunt virus. Biochem. J. 49, 401 . 